\title{
TRIAGEM FITOQUÍMICA DE POLPA DE FRUTOS DE ABACATEIRO 'HASS' CULTIVADOS EM TRÊS CORAÇÕES, MG.
}

\author{
Hiani A. Lima Ferreira ${ }^{1}$ \\ Fábio Oseias dos Reis Silva ${ }^{2}$ \\ Marcelo Caetano de Oliveira ${ }^{3}$ \\ Fabricio Darley Paixão Fernandes ${ }^{4}$ \\ José Darlan Ramos ${ }^{5}$
}

Resumo: Sabe-se que a composição química do abacate varia em função das variações fenológicas nas diferentes regiões, dessa forma é de grande relevância a pesquisa acerca desse tema para a expansão do cultivo do abacateiro. Nesse contexto, objetivou-se no presente trabalho avaliar a composição fitoquímica de frutos da variedade de abacateiro cultivado em Três Corações, Minas Gerais. De acordo com os resultados concluiu-se que estão presentes na variedade do abacateiro 'Hass' açucares redutores, proteínas e aminoácidos, sesquiterpenlactonas e lactonas, esteróides, derivados de cumarina, saponinas espumídicas e alcalóides. Pela presença destes compostos deduz-se que o fruto apresenta propriedades nutricionais indicadas para o consumo humano.

Palavras-chave: Persea americana Mill.; Composição; Óleo.

\footnotetext{
1 Mestrado em Agricultura Tropical/ Universidade Federal do Espírito Santo, Brasil. E-mail: hiani.ferreira@gmail.com.

2 Pós-Doutorado em Agricultura Tropical/Universidade Federal do Espírito Santo, Brasil. E-mail: foseias@yahoo.com.br.

${ }^{3}$ Professor/ Instituto Federal de Educação, Ciência e Tecnologia de Mato Grosso do Sul, Brasil. E-mail: caetanocaldas@hotmail.com.

4 Professor/ Centro Estadual Integrado de Educação Rural, Brasil. E-mail: fabricioruralrj@yahoo.com.br

${ }^{5}$ Professor/ Universidade Federal de Lavras, Brasil. E-mail: darlan@dag.ufla.br.
} 